\section{Edyeasáa

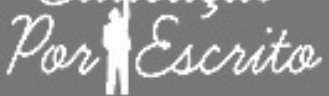

ARTIGO

\section{Editor}

Alexandre Anselmo Guilherme PUCRS, RS, Brasil

\section{Editor Assistente}

Cibele Cheron

PUCRS, RS, Brasil

\section{Editores Associados}

Bruno Antonio Picoli

Universidade Federal da Fronteira Sul, Chapecó, SC, Brasil

Pricila Kohls dos Santos Universidade Católica de Brasília, Brasília, DF, Brasil

Renato de Oliveira Brito

Universidade Católica de Brasilia, Brasilia, DF, Brasil

Elisa Ustarroz

PUCRS, Porto Alegre, RS, Brasil

\section{ISSN 2179-8435}

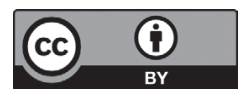

Este artigo está licenciado sob forma de uma licença Creative Commons Atribuição 4.0 Internacional, que permite uso irrestrito, distribuicăo e reprodução em qualquer meio, desce corretamente citada

\title{
Percepção da importância das tecnologias digitais por docentes dos cursos de formação inicial de professores no município de Crateús, CE
}

\author{
Perception of the importance of digital technologies by teachers of initial \\ teacher training courses in the municipality of Crateús, $C E$
}

\author{
Francisco Nunes Sousa Moura $\odot^{1}$ \\ Shirliane de Araújo Sousa $\oplus^{1}$ \\ Jones Baroni Ferreira Menezes $\oplus^{1}$ \\ ${ }^{1}$ Universidade Estadual do Ceará, Fortaleza, CE, Brasil.
}

\section{RESUMO}

As instituições de ensino, sobretudo as de educação básica, não podem ficar alheias quanto à formação dos alunos para utilização das tecnologias digitais em suas práticas cotidianas. Entretanto, é preciso que os docentes dos cursos de licenciatura tenham preparação inicial para instrumentalizar os licenciandos para a prática docente. Assim, o objetivo deste trabalho é averiguar a concepção dos docentes dos cursos de licenciatura da cidade de Crateús, CE, quanto à importância das tecnologias de informação e comunicação (TIC) para formação dos alunos de licenciatura. Para realização desta pesquisa qualitativa, aplicou-se questionário estruturado aos docentes de seis cursos de licenciatura ofertados por instituições públicas de ensino superior no município de Crateús, CE, indagando sobre o domínio e a percepção das TIC como potencial didático. Observou-se que os 41 professores possuem contato com os recursos tecnológicos. Desses, 27 docentes não tiveram formação para uso em sua prática pedagógica, entretanto, todos os professores consideram relevante a inserção dessas ferramentas no ensino. Nesse sentido, constata-se o conhecimento dos docentes com diversas ferramentas tecnológicas, as quais podem ser adaptadas para práticas pedagógicas e aceitabilidade destas ferramentas como potencial pedagógico ao reconhecer a sua relevância para o ensino.

Palavras-chave: TIC. Formação de professores. Ensino superior.

\section{ABSTRACT}

Institutions of education, especially the basic education, can not remain oblivious to the training of students to use these tools in their daily practices. However, it is necessary that the teachers of the degree courses have initial preparation to prepare the graduates for the teaching practice. Thus, the objective of this work is to 
investigate the conception of the teachers of the undergraduate courses of the city of Crateús-CE regarding the importance of information and communication technologies for the training of undergraduate students. To carry out this qualitative research, a structured questionnaire was applied to the teachers of 6 undergraduate courses offered by public higher education institutions in the city of Crateús, Ce, inquiring about the domain and the perception of ICT as didactic potential. It was observed that the 41 teachers have contact with the technological resources. Of these, 27 teachers did not have training to use in their pedagogical practice, however, all teachers consider relevant the insertion of these tools in teaching. In this sense, the knowledge of the teachers with several technological tools is verified, which can be adapted for pedagogical practices and the acceptability of these tools as pedagogical potential when recognizing their relevance to teaching.

Keywords: ICT. Teacher training. Higher education.

\section{Introdução}

Tá atualmente uma constituição de uma cultura digital, a qual denota inovações em práticas sociais e instiga a construção de novas inclusões educativas nas instituições de ensino pautadas na utilização de ferramentas tecnológicas, mesmo que essas não estejam fisicamente presentes nas escolas. A cultura digital é um processo avassalador na sociedade e as instituições de ensino não podem ficar alheias quanto a tais modificações nos contextos sociais (NUNES et al., 2014).

Assim, é corroborada a necessidade de inclusão das tecnologias para reconfigurar as formas de trabalho e atuação docente, isso decorre devido a estes recursos tecnológicos definirem novos discursos sobre o ensino, subsidiado com novas metodologias para geração de aprendizagem (BARRETO et al., 2004). Essa reflexão pode modificar o atual cenário de trabalhos que referenciam as TIC com diferentes sentidos e que, assim, impossibilitam a leitura e a interpretação de forma singular. Salienta-se também que as múltiplas formações iniciais podem modificar esse cenário na educação e instigar a construção de novas pesquisas com relação mutualística entre tecnologia e educação.

Seguindo essas perspectivas, os Parâmetros Curriculares Nacionais (BRASIL, 2000) denotam objetivos e competências a serem atingidos ao utilizar a informática no contexto educacional, entre eles, destacam-se: a necessidade de compreender principais conceitos computacionais, ferramentas e funções da informática, bem como reconhecer tais instrumentos como inovadores para a aprendizagem e no processo de construção do conhecimento. Nese contexto, é preciso que os alunos de licenciatura tenham a formação pautada nesse conceito de importância das novas tecnologias e a vivência de experiências exitosas. 
Assim, é preciso que os docentes do ensino superior aceitem as ferramentas tecnológicas como recursos essenciais na formação dos alunos de licenciatura que atuarão como docentes na educação básica. Essa aceitabilidade é intensificada com o conhecimento dos professores quanto a diversos recursos tecnológicos, assim como a participação em formações para o uso didático das tecnologias de informação e comunicação.

$\mathrm{Na}$ perspectiva de Pontes (2000), as tecnologias representam um meio de obter, transformar e construir informações proporcionadas por meio de comunicações a distância e trabalhos coletivos, apesar dos corpos físicos estarem distantes. O autor destaca também, a necessidade de incluir as tecnologias de informação e comunicação na formação inicial de professores tendo em vista as possibilidades de despertar uma mente crítica nos futuros profissionais ingressantes da educação básica quanto à aplicação de tais ferramentas no contexto educacional, assim como instigar uma reflexão para satisfazer ao máximo a aplicação desses recursos tecnológicos na prática docente.

Nesse sentido, é preciso que os docentes do ensino superior tenham vivenciado diversas experiências exitosas para proporcionar novas experiências aos alunos de licenciatura. De acordo com Bergamo (2010), as experiências exitosas vivenciadas durante o processo de formação são reproduzidas ao chegar à educação básica. Isso se intensifica com aplicação consciente das potencialidades destes recursos para efetivar a prática de ensino e aprendizagem.

Correia e Santos (2013) enfatizam que o atual processo de ensino e aprendizagem está interligado à comunicação, isso decorre em parte da contínua frequência de professores e alunos nas redes sociais. Para Barreto et al. (2004), as TIC tornaram-se importantes ferramentas de discurso para formação de alunos e concretização das formas de ensino aplicadas pelos professores.

Nessas perspectivas, o presente trabalho tem o objetivo geral de averiguar a concepção dos docentes dos cursos de licenciatura da cidade de Crateús, CE, quanto à importância das tecnologias de informação e comunicação para formação dos alunos de licenciatura, mediante objetivos específicos de identificar as ferramentas de domínio desses docentes; averiguar a participação em cursos de formação para aplicação didática dos recursos tecnológicos pelos professores e constatar a percepção dos docentes da relevância desses recursos tecnológicos para formação dos alunos.

\section{Aspectos metodológicos}

A presente pesquisa procede de paradigma pós-positivista, possuindo abordagem qualitativa. Creswell (2007) define o paradigma pós-positivista como filosófico, ressaltando que as causas determinam os resultados. Esse pressuposto torna-se importante para verificar a realidade que antecede e circunde a prática docente no ensino superior, no tocante de constatar a atuação docente nos cursos de licenciatura referente ao uso pedagógico 
das tecnologias digitais atualmente. Segundo Silveman $(2009$, p. 31) a abordagem qualitativa é uma questão de caráter significativo para "[...] entender as categorias dos participantes e ver como elas agem em atividades concretas $[\ldots] "$.

Quanto aos procedimentos metodológicos, optou-se por coletar os dados por intermédio do uso de um questionário, investigando informações pessoais e profissionais dos pesquisados. Esse trabalho foi realizado entre os meses de março a dezembro de 2017. Em conseguinte, as respostas dos pesquisados foram categorizados da seguinte forma: domínio das ferramentas tecnológicas, formação para uso na prática docente, percepção da relevância dos recursos tecnológicos formação acadêmica dos alunos de licenciatura.

A cidade de Crateús, na qual foi realizada a presente pesquisa, está localizada na microrregião Sertões de Crateús e possui cerca de $350 \mathrm{~km}$ de distância da cidade de Fortaleza, capital do estado do Ceará. Limita-se com as cidades de Ipaporanga, Independência, Novo Oriente e com o estado do Piauí (IBGE, 2015). Esse município é contemplado com três instituições públicas de ensino superior: Instituto Federal de Educação, Ciências e Tecnologia do Ceará; Universidade Estadual do Ceará; e Universidade Federal do Ceará, entretanto apenas as duas primeiras instituições de ensino ofertam cursos para formação de professores, sendo os cursos de Física (2014) ${ }^{1}$, Letras (2012) ${ }^{1}$ e Matemática $(2010)^{1}$ ofertados pelo Instituto Federal de Educação, Ciências e Tecnologia do Ceará - campus Crateús (IFCE/

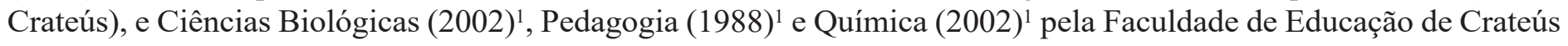
- Universidade Estadual do Ceará (FAEC/UECE). Os pesquisados, os docentes efetivos e os substitutos atuantes nos seis cursos de licenciatura, responderam quanto ao conhecimento do manuseio de ferramentas tecnológicas; a formação para uso das TIC na prática pedagógica.

A quantificação de professores atuantes nos cursos de licenciatura das universidades supracitadas e participantes da presente pesquisa encontra-se na Tabela 1. Os sujeitos desta pesquisa têm suas identidades preservadas, sendo codificados com as letras iniciais dos cursos que estão vinculados (CB, F, L, M, P ou Q), seguindo uma sequência crescente de organização da tabulação dos dados pelo pesquisador.

Os docentes foram convidados a participar da pesquisa, a qual teve os preceitos éticos respeitados pelo pesquisador, apresentando-os o Termo de Consentimento Livre Esclarecido, e reitera-se, que nesta pesquisa, os entrevistados estavam conscientes quanto à resolução do questionário, que foi baseado e adaptado de Gonçalves (2005), não sofrendo nenhum risco mental e/ou físico, possuindo suas identidades preservadas e podendo desistir a qualquer momento de participar da pesquisa. Dessa forma, este trabalho segue os preceitos éticos preconizados pela resolução 510/2016 do Conselho Nacional de Saúde (CNS). O trabalho faz parte do projeto intitulado: "A utilização da

\footnotetext{
1 Ano de implantação dos cursos nas instituições de ensino superior.
} 
tecnologia no processo educacional: uma realidade de Crateús-Ce", sido aprovado pelo Comitê de Ética da instituição proponente, sob o número de protocolo 60232716.2.0000.5534.

Tabela 1. Quantificação dos professores por curso e os que participaram da pesquisa

\begin{tabular}{lcc}
\hline & Quant. de professores por curso. & $\begin{array}{c}\text { Quant. de professores que } \\
\text { participaram da pesquisa. }\end{array}$ \\
Ciências Biológicas (UECE) & 10 & 09 \\
Física (IFCE) & 05 & 03 \\
Letras (IFCE) & 08 & 07 \\
Matemática (IFCE) & 08 & 05 \\
Pedagogia (UECE) & 16 & 12 \\
Química (UECE) & 07 & 05 \\
Total & $\mathbf{5 4}$ & $\mathbf{4 1}$ \\
\hline
\end{tabular}

Fonte: Dados obtidos do site IFCE e UECE durante a aplicação dos questionários.

\section{Resultados e discussão}

Nessa pesquisa houve um total de 41 participantes dos 49 questionários aplicados. Entretanto, 8 professores não devolveram o questionário, mesmo com várias tentativas de contato; quanto aos demais 4 docentes não compareceram à instituição de ensino no período de realização da pesquisa e um professor não aceitou participar da presente pesquisa.

Dentre os professores que responderam ao questionário, temos 23 do gênero masculino e 18 do feminino, com: idade variando entre 25 a 54 anos; período de magistério e vínculo com a instituição de ensino com alternação dentre 1 mês e 25 anos. Quanto ao nível final de formação dos pesquisados: 4 professores são especialistas; 20 docentes possuem mestrado; 15 docentes são doutores e 2 professores possuem a certificação de pós-doutorado.

\section{Domínio das tecnologias digitais pelos participantes da pesquisa}

Aos docentes foi solicitado que assinalassem no questionário as funções tecnológicas que eles dominavam. O intuito era identificar as tecnologias digitais conhecidas e utilizadas pelos professores em suas atividades cotidianas, 
seja de cunho pessoal ou profissional. Seguindo essa vertente é perceptível o conhecimento dos docentes sobre diversas ferramentas tecnológicas, como se observa abaixo.

Gráfico 1. Funções tecnológicas de domínio dos participantes da pesquisa

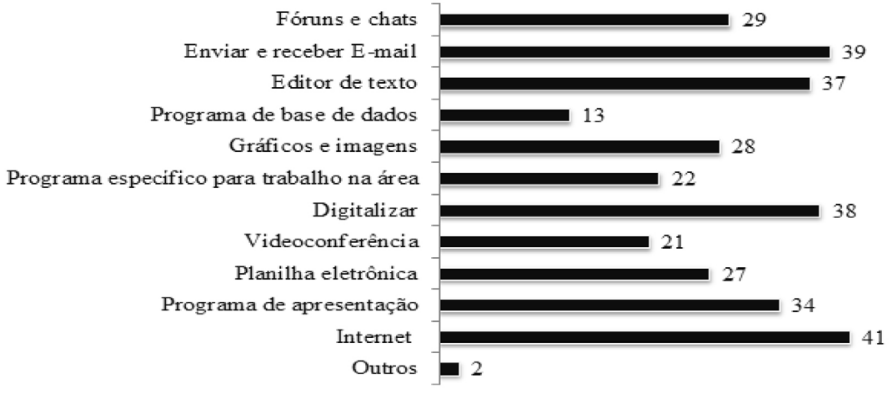

Fonte: elaborado pelo autor.

Diante das respostas dos professores, destaca-se que cerca de $90 \%$ dos recursos tecnológicos listados no questionário são de conhecimento e domínio por no mínimo $50 \%$ dos docentes. Dessa forma, constata-se, a possibilidade da aplicação desses recursos na prática docente, uma vez que os professores conhecem a sua utilização e podem refletir sobre a aplicação de forma pedagógica durante atuação docente. Os achados acima podem se justificar pelo fato da demanda de professores jovens atuando no ensino superior, sendo que a aplicação das TIC na sociedade ocorreu em média há 40 anos.

Lima (2016) enfatiza que a globalização e a disseminação de informações pelos recursos tecnológicos são pontos norteadores para o desenvolvimento das tecnologias digitais nos diversos eixos da sociedade, tais como no mundo do trabalho, lazer e até mesmo na vida privada das pessoas. Para a autora, a tecnologia é vista como ferramenta indissociável nas atividades da sociedade, tendo em vista que permite a troca de informações e a interação entre diferentes indivíduos.

A implantação das tecnologias digitais no contexto contemporâneo tem ocorrido de forma acelerada, propiciando mudanças nos diferentes setores sociais em um curto período de tempo. Essas alterações são intensificadas com o surgimento da internet, a qual se tornou ainda mais acessível (e sem fio) a qualquer dispositivo eletrônico, permitindo um avanço na criação de benefícios e facilidades no desenvolvimento de diversas atividades (KOHN; MORAES, 2007). 
Ainda sobre os resultados acima, identifica-se o contato unânime dos professores com as tecnologias digitais ao constatar a assinalação em $100 \%$ dos mesmos diante uso da internet, que pode ser utilizada como importante fonte de pesquisa para enriquecer o conhecimento em sala de aula, assim como em busca de plataformas virtuais para utilizar com os alunos e inovar a prática docente, entre outras funcionalidades. Maia (2007) conceitua a internet como importante meio de conexão entre a sociedade, possibilitando interações entre os envolvidos. Nesse contexto, a internet pode ser empregada como recurso para obtenção de novos aprendizados do docente para as aulas e visualização de diversas experiências exitosas, estimulando a inovação em diversas práticas cotidianas, entre elas a de cunho de docente.

Em estudo com similitude à presente pesquisa, corroborando-a nele, Rolando et al. (2015), também observaram o conhecimento e uso de diversas ferramentas tecnológicas pelos professores pesquisados em diversos âmbitos de aplicação das ferramentas tecnológicas, destacando em maior potencialidade a utilização frequente da internet. No entanto, os autores ressaltam que apesar do conhecimento referente a essas funções tecnológicas, há uma limitação da aplicação de tais ferramentas de forma pedagógica para concretizar a prática docente, justificado pelo desconhecimento dos docentes sobre o uso pedagógico destas ferramentas no ensino.

Seguindo esse pressuposto, Balani (2012) enfatiza sobre a necessidade da formação eficiente de professores para despertar o interesse do uso das ferramentas tecnológicas na prática docente. O posicionamento da autora instiga conhecer o percurso de formação dos professores, sobretudo dos cursos de licenciatura, assim como a sua trajetória metodológica com utilização das tecnologias digitais para contribuição no processo de ensino e aprendizagem. Desta forma, abordaremos no próximo subtópico sobre a importância do uso das tecnologias na formação dos professores.

\section{Formação para uso das tecnologias digitais na prática docente}

Ao serem questionados sobre a formação quanto ao uso das tecnologias de informação e comunicação no contexto educacional, uma parcela de 27 professores respondeu que não tiveram tal formação durante as suas preparações acadêmicas, tendo que realizar o aprendizado em cursos de informática básica, na experiência profissional e/ou em leituras de artigos na internet. Essa realidade denota a falta da aplicação destas ferramentas tecnológicas na grade curricular dos cursos para formação de professores.

Contrariamente aos achados anteriores, 14 docentes tiveram uma formação para uso das tecnologias no contexto educacional. Entretanto, é importante salientar que apenas 1 professor relatou ter tido tal formação durante a formação inicial (graduação), enquanto os demais docentes relataram aprendizado na formação continuada (especialização e mestrado) ou formação complementar nos cursos relacionados a temática. 
A preparação docente para utilização das tecnologias digitais tem sido uma discussão ao longo dos anos, prevalecendo até os dias atuais. As instituições de ensino têm incluído diversos recursos tecnológicos para os professores estarem inserindo em sua prática pedagógica, entretanto, falta a formação para adequar essas ferramentas tecnológicas no contexto docente, agregando conhecimento técnico e pedagógico nas aulas (PRATA-LINHARES; ARRUDA, 2017).

Silva e Garíglio (2010) consideram de suma importância à formação dos professores para utilização das TIC na prática pedagógica, uma vez que as políticas públicas exigem a inserção destes recursos tecnológicos no tocante de preparar os alunos para atuação cidadã. Para esses autores, a formação expandiria o conhecimento dos docentes, no intuito de aproximá-los das ferramentas tecnológicas, deixando-os de serem apenas transmissor de técnicas com ferramentas as quais não construíram. Desta forma, o relato dos autores é importante para refletir sobre as problemáticas da não formação dos professores, tendo em vista a sua falta de conhecimento na construção das ferramentas tecnológicas, utilizando um produto pronto, o que carece a realização de estudos para conhecer suas formas de aplicação.

A preparação adequada dos professores para uso das tecnologias na educação contribui também para amenizar ou até mesmo suprir algumas problemáticas encontradas por estes para utilizar as ferramentas tecnológicas na prática docente, entre elas ressalta-se a insegurança ou receio dos professores no caso destas ferramentas não alcançarem os objetivos desejados ou ocorrer falhas durante a execução da atividade, sendo isso resultado de uma experiência não consolidada durante a sua formação inicial ou continuada (ROSA, 2012).

As universidades têm a competência de preparar os licenciandos para atuar de acordo com as exigências das políticas públicas. Compete a essas instituições também contribuir na formação do futuro professor com suas práticas pedagógicas, no tocante de articular metodologias para atrair os alunos para o conhecimento, resultando em um compasso entre a formação inicial e sua prática pedagógica (BONADIMAN; NOMENMACHER, 2013). Assim, nas respostas dos pesquisados, observamos que apenas um docente teve o contato com as ferramentas tecnológicas voltadas para o ensino na formação inicial.

As constatações nos itens anteriormente citados vão de encontro aos relatos de Dorneles e Bujes (2012), em que discorrem sobre a falta de formação tecnológica nas instituições de ensino superior, sobretudo na formação inicial, e quando ocorre tal processo não é totalmente eficaz para suprir as necessidades de inclusão das ferramentas tecnológicas no contexto educacional, uma vez que não atingem todas as suas potencialidades ao serem aplicadas na prática docente.

Em conseguinte, os professores foram questionados sobre a sensação da necessidade de formação nas áreas tecnológicas. Um total de 35 docentes relatou sentir tal necessidade, justificado pelo fato do potencial destas 
ferramentas para moldar a prática docente; de permitir acompanhamento das atuais mudanças no mundo, bem como contribuir para o aprendizado dos alunos e inovação pedagógica, entre outras falas, como é possível observar abaixo. Quanto aos outros 6 docentes, apesar de informarem ter conhecimentos mínimos relacionados às tecnologias educacionais, eles consideram suficiente para aplicação em suas práticas de ensino.

CB4 - "É necessário capacitar o professor para poder incorporar as TIC em sua prática docente.”

CB5 - "Acredito que ajudará o professor a ser mais capacitado lidando melhor com as constantes mudanças globais e as novas necessidades de ensino."

“- Nas licenciaturas em que não há, deveria haver disciplinas realizadas ao uso das TIC no ensino, para que o professor em formação inicial pudesse conhecer e desenvolver estratégias produtivas para ressignificar o seu agir na sala de aula de uma sociedade cada vez mais conectada." (L1)

"Gostaria de aprender e manipular as TICs na área de educação inclusiva para ajudar os alunos com deficiência." (L2)

"Poderia entrar nas matrizes de licenciaturas, o uso de tecnologias. Futuramente isso será básico e comum, então devemos nos aperfeiçoar logo." (M2)

“- Muitas vezes os imprevistos acontecem não sabemos resolver mais simples na utilizadas dos equipamentos, por sua variedade e complexidade. Sinto necessidade de educação forma na área de T.I.C., o que aprendi foi na prática e com ajuda de filho, amigo, colega de instituto e até mesmo pesquisando na internet." (P11)

Constata-se nos relatos dos pesquisados os seus anseios para formação relacionada ao uso das tecnologias na prática docente, uma vez que reconhecem o avanço da globalização e os impactos destas ferramentas para formação do aluno. Isso decorre segundo Maciel (2004) e Rodrigues (2012) devido à formação docente ser uma forma deste estar preparado para o uso das tecnologias como ferramentas didáticas, e contribuindo com os alunos para preparação cidadã.

Outro destaque realizado nas respostas dos professores consiste na aplicação das ferramentas tecnológicas para suprir algumas dificuldades presentes na prática docente, como o caso de lidar com alunos deficientes. Melara, Rampelotto e Linassi (2015) discorrem sobre a importância das tecnologias para promover a troca de conhecimento entre as pessoas, visto que os seus distintos recursos buscam aproximação entre os sujeitos envolvidos. 
Domingos, Almeida e Barreto (2014) relatam sobre os benefícios da inclusão de pessoas com deficiência, assim como também ao mesmo tempo a inclusão das tecnologias de informação e comunicação nas instituições de ensino, sendo que estas ferramentas com potencial didático beneficiam para a discussão entre os alunos com deficiência e o professor.

Assim, as tecnologias possibilitam uma reflexão sobre as necessidades de cada individuo, resultando em uma reflexão que permita solucionar determinadas realidades, entre elas as de comunicação e interação entre as pessoas. Nesse sentido, cada peculiaridade deve ser considerada e aplicada no meio social, tendo em vista a formação de uma sociedade com uma heterogeneidade de cidadãos (SANTOS; CARLI; CANO, 2011). Essas possibilidades são intensificadas pela inclusão das ferramentas de ensino na prática docente, possibilitadas pela formação de qualidade.

Em outras respostas elencadas acima, verifica-se a solicitação de alguns docentes para adesão das tecnologias educacionais na grade curricular dos cursos de licenciatura, visto o seu crescimento na sociedade. Concomitante, esta situação foi refletida por um dos pesquisados, como é possível observar abaixo, que também sente a necessidade da formação para uso das TIC no contexto educacional.

"A pergunta que deixo, é de onde tirar carga horária das grades do curso para colocar mais disciplinas falando sobre TIC na educação, isso feito de maneira eficiente, sem prejudicar os outros tópicos que devem ser abordados nas licenciaturas e sem sobrecarregar os discentes que já lhe dão como uma grade curricular muito cheia." (CB4)

Apesar de o docente considerar relevante a inserção sobre o uso das tecnologias na grade curricular, é perceptível sua preocupação quanto às demais disciplinas nos cursos de licenciatura. No entanto, Sá e Santos (2017) ao relatarem sobre a grade curricular dos cursos de licenciatura, destacam sobre a inserção de um maior número de disciplinas específicas, limitando as disciplinas de cunho pedagógico, as quais são primordiais para a formação dos alunos de licenciatura. Neste sentido, é preciso uma avaliação relacionada às ofertas na grade curricular, uma vez que conhecimentos específicos e pedagógicos devem trilhar os mesmos caminhos.

Outra importante observação incide na aplicação das ferramentas tecnológicas não ocorrer apenas na grade curricular, mas sim na prática dos professores de licenciatura. A preparação docente para utilização das tecnologias além de potencializadas com aplicação de disciplinas na grade curricular dos cursos de licenciatura, essas também podem aplicadas na prática docente dos formadores de professores, todavia, Martini e Bueno (2014) complementam que os cursos de licenciatura na atualidade, mesmo com as diversas mudanças no ensino, ainda sofrem com os paradigmas tradicionais, os quais a troca de conhecimento é realizada com listas de exercícios e repetição expositiva dos conteúdos. 
Neste sentido, é preciso que os professores sejam adeptos ao uso de novas metodologias de ensino, sobretudo as tecnologias digitais em que conheçam a importância destas ferramentas didáticas para a formação do aluno. Neste sentido, no próximo subtópico relataremos sobre a concepção dos professores pesquisados quanto a relevância da utilização de ferramentas tecnológicas na prática pedagógica.

\section{Concepção da relevância dos recursos tecnológicos como ferramenta didática}

Os professores foram questionados se consideravam os recursos tecnológicos importantes para o processo de ensino e aprendizagem, tendo sido respondido afirmativamente de forma unânime. Eles citaram as ferramentas tecnológicas como metodologias complementares as tradicionais; contribuem para o contato mais acelerado com os conteúdos; as atratividades oportunizadas as aulas; a capacidade de elucidar as aulas, entre outros benefícios, como exemplo segue alguns relatos.

"As TIC facilitam e são metodologias complementares as tradicionais aulas expositivas; facilitam a comunicação entre o professor e aluno; e tornam as aulas mais interativas." (CB1)

E outro:

"As TIC podem ajudar o professor a planejar e a ministrar aulas mais produtivas e mais atraentes para os alunos, bem como podem oportunizar aos alunos o acesso a ferramentas indispensáveis atualmente para a interação social." (L1).

E a análise segue:

"Porque o aprendizado notoriamente torna-se facilitado com uso de tecnologias. As aulas ficam mais interessantes, pois as aplicações práticas são melhores conduzidas." (M2).

Outro docente reflete em sua resposta:

"A vantagem é poder utilizar os recursos da tecnologia para evidenciar os fenômenos que ocorrem no dia a dia e assim reduzir esse obstáculo que existe com as disciplinas de ciências.” (Q2)

É notório nos relatos dos professores a intervenção dos recursos tecnológicos para modificar o comportamento dos alunos na aula ao utilizá-las na prática docente, resultado da atratividade destas ferramentas para adquirir 
conhecimento. As atratividades das ferramentas complementares as tradicionais são destacadas por Albrecht e Krüger (2013) os quais relatam que aulas apenas expositivas não chamam mais a atenção dos discentes, e por isso tornase necessário que os professores utilizem diferentes metodologias para terem práticas mais exitosas e eficazes ao processo de ensino e aprendizagem.

Para alguns docentes, as tecnologias contribuem para deixar as aulas mais produtivas no tocante de possibilitar uma melhor visualização de conceitos. Couto e Prado (2015) enfatizam sobre os benefícios das tecnologias para tornar os alunos construtores do próprio conhecimento, tornando-se sujeitos ativos em sociedade. Assim, observa-se a influência positiva das TIC para formação dos alunos, acrescentado pela praticidade inclusa em suas aulas.

Ao serem questionados sobre as desvantagens do uso das tecnologias na prática docente, os professores relataram sobre as exigências de um planejamento mais detalhado; possibilidade de "alienação" ao ignorar outras estratégias metodológicas; falhas nos equipamentos durante a utilização dos recursos tecnológicos; e uma acomodação do docente e discente, como é perceptível nos relatos abaixo.

"O ponto negativo é somente que a possibilidade de alienação, quando o discente não utiliza de outros recursos didáticos.” (CB3)

"A desvantagem é a falta de tempo para planejamento com ferramentas tecnológicas." (F2)

"Quando o data show não funciona, às vezes o professor não se organiza e fico preso aquela ferramenta." (L2).

"Acomodação docente e discente em alguns casos, quando não se tem compromisso real com a docência.” (P3).

Apesar do maior contato com as tecnologias digitais, conhecendo os seus recursos e funcionalidades, há uma limitação dos professores das universidades e alunos de licenciatura referente à aplicação destas como estratégias de forma didática, o que aponta a importância da aquisição de experiências ao longo da formação docente, acrescentando a interdisciplinaridade para maior eficácia da aprendizagem (SILVA, 2015).

Constatam-se nas respostas dos professores uma falta de segurança para utilização das tecnologias ao falarem sobre acomodação docente e falha de equipamentos, resultado esse agregado à falta de formação. Essas observações são pontos norteadores para identificar uma falta de aceitabilidade dos professores, visto que para o planejamento adequado e êxito no processo de ensino e aprendizagem é preciso que os professores conheçam as ferramentas propostas para utilização em sala de aula, bem como possam dominá-las em sua prática docente (SEEGER; CANES; GARCIA, 2012). 
Nesse sentido, é compreensível uma resistência dos docentes para utilização dos recursos tecnológicos em suas práticas de ensino. Essa realidade é constatada ao observar a utilização de métodos tradicionais como o lápis e caderno para ilustrar conteúdos que já são aplicados e acessíveis no computador, como exemplo, cita-se o uso do mapa-múndi nas aulas de geografia, enquanto há a praticidade e eficiência do Google Earth para apresentar as diferentes cidades, regiões e países do mundo (MOURA; BRANDÃO, 2013).

Nos achados de Marin (2012), os docentes reconhecem a relevância das tecnologias na prática docente, tendo em vista que identificam as vantagens de inserir esses recursos nas aulas. Entretanto são perceptíveis as desvantagens em virtude das formas utilizadas pelos professores, sem caráter pedagógico e a falta de contato com os recursos tecnológicos desde as suas formações básica, o que resulta no despreparo para aplicação com os alunos. Assim, o autor discorre da importância de inserir as tecnologias nas grades dos cursos de pós-graduação, bem como integrar articulação da prática nos cursos de licenciatura.

Feldkercher e Manara (2012) relatam que a falta de conhecimento dos alunos também pode ser representada como desvantagem na consolidação da aplicação didática das ferramentas tecnológicas, tendo em vista a possível despreparação do docente, agregada ao não domínio dos alunos nas ferramentas tecnológicas. Neste sentido, conhecer a relevância das tecnologias para formação dos alunos, bem como identificar as desvantagens destes recursos contribui para o docente refletir a aplicação destes recursos tecnológicos em suas atividades de ensino.

\section{Considerações finais}

Os recursos tecnológicos têm possibilitado uma nova forma dos alunos adquirirem conhecimento e efetivar a interação entre professores e alunos, uma vez que esses possuem acesso à informação e podem utilizá-las em ambiente de aprendizado, necessitando apenas que o professor cumpra os requisitos de conhecimento das ferramentas tecnológicas e aceitem tais recursos como promissoras para o processo de ensino e aprendizagem.

Seguindo esse pressuposto, é perceptível o conhecimento dos docentes relacionado a diversas ferramentas tecnológicas, no tocante de utilizar em diversos contextos de suas realidades, em alguns casos há consonância nas ferramentas utilizadas entre eles, o que demonstra o contato dos professores de licenciatura com as tecnologias digitais. Em complemento, os docentes reconhecem em unanimidade a importância de aplicar as TIC na prática docente, uma vez que possibilita a inovação das práticas de ensino, essa vantagem soma-se a outras, tais como complemento das metodologias de ensino tradicional que juntas facilitam a aquisição de conhecimento.

Quanto à formação, apesar de todos os docentes possuírem formação continuada, a maioria relata não ter ocorrido essa abordagem sobre as tecnologias digitais na preparação inicial, o que denota a possibilidade de ainda 
haver necessidade da aplicação desses recursos tecnológicos na prática pedagógica dos professores universitários para formação consolidada dos alunos de licenciatura.

Nesse sentido, identificamos o contato dos professores de Crateús, CE, com diversas ferramentas tecnológicas, necessitando apenas que adaptem essas ferramentas para as suas práticas pedagógicas, e assim, possibilitem a formação de conhecimento técnico (alunos conhecedores de diversas ferramentas tecnológicas) e pedagógico (utilização destas ferramentas tecnológicas para proporcionar momentos prazerosos e de conhecimento aos sujeitos envolvidos).

\section{Referências}

ALBRECHT, L. D.; KRÜGER, V. Metodologia tradicional x Metodologia diferenciada: a opinião de alunos. In: EDEQ, 33., 2013, Ijuí. Anais [...] Ijuí: Unijuí, 2013.

BALANI, C. Recursos tecnológicos: uma nova perspectiva para o ensino de ciências. 2012. 32 f. Trabalho de Conclusão de Curso (Especialização) - Universidade Tecnológica Federal do Paraná, Medianeira, 2012. https://doi.org/10.21474/ijar01/1535

BARRETO, R. G. Tecnologia e educação: trabalho e formação docente. Educação \& Sociedade, v. 25, n. 89, p. 1181-1201, 2004. https://doi.org/10.1590/s0101-73302004000400006

BERGAMO, M. O uso de Metodologias diferenciadas em sala de aula: uma experiência no Ensino Superior. Revista Eletrônica Interdisciplinar, v. 2, n. 4, 2010.

BONADIMAN, H.; NONENMACHER, S. E. B. O gostar e o aprender no ensino de Física: uma proposta metodológica. Caderno Brasileiro de Ensino de Física, v. 24, n. 2, 2007. https://doi.org/10.5007/2175-7941.2014v31n3p722

BRASIL, Ministério da Educação. Parâmetros Curriculares Nacionais: Ensino Médio. Brasília, 2000.

CORREIA, R. L.; SANTOS, J. G. A Importância da Tecnologia da Informação e Comunicação (TIC) na Educação a Distância (EAD) do Ensino Superior (IES). Revista Aprendizagem em EAD, v. 2, 2013. https://doi.org/10.18264/eadf.v6i3.419

COUTO, M.; PRADO, M. Uso da tecnologia nas artes visuais em sala de aula. Revista Educação, Artes e Inclusão, v. 11, n. 2, p. 141-167, 2015. https://doi.org/10.5965/198431781122015141

CRESWELL, J. W. Projeto de pesquisa: métodos qualitativo, quantitativo e misto. 3. ed. PORTO ALEGRE: ARTMED, 2010. https://doi.org/10.26512/les.v13i1.11610 
DOMINGOS, R.; ALMEIDA, G. B. S.; BARRETO, S. M. da C. O papel das Tecnologias de Informação e Comunicação (TICs) na inclusão de alunos com necessidades educacionais especiais no Centro Universitário do Espírito Santo - UNESC. Educação Por Escrito, v. 5, n. 1, p. 98-110. https://doi.org/10.15448/2179-8435.2014.1.15857

DORNELlES, L. V.; BUJES, M. I. E. (org.). Educação e infância na era da informação. Porto Alegre: Mediação, 2012.

FELDKERCHER, N.; MANARA, A. S. O uso das tecnologias na educação à distância pelo professor tutor. Revista Iberoamericana de Educación a Distancia, v. 15, n. 2, p. 31, 2012. https://doi.org/10.5944/ried.2.15.597

GONÇALVES, M. T. L. A formação de professores para as tecnologias de informação e comunicação: novos desafios ao ensino médio. 2005. 200 f. Dissertação (Mestrado) - Curso de Educação, Centro de Educação, Universidade Estadual do Ceará, Fortaleza, 2005. https://doi.org/10.1590/s0101-73302011000300004

IBGE. Instituto Brasileiro de Geografia e Estatística - cidade Crateús. 2015. Disponível em: http://cidades.ibge.gov.br/xtras/ perfil.php?codmun=230410. Acesso em: 10 maio 2017.

KOHN, K.; MORAES, C. H. O impacto das novas tecnologias na sociedade: conceitos e características da Sociedade da Informação e da Sociedade Digital. In: CONGRESSO BRASILEIRO DE CIÊNCIAS DA COMUNICAÇÃO, 30., 2007, Santos. Anais [...], Santos, 2007. https://doi.org/10.15603/2175-7755/cs.v29n49p229-233

LIMA, D. C. B. P. Tecnologias, educação e formação: conceitos, inclusão e iniciativas. In: ANDERI, Eliane Gonçalves Costa; TOSCHI, Mirza Seabra. Inclusão Digital e Social: conhecimento e cidadania. Goiás: Ueg, 2016. p. 29-48.

MACIEL, J. S. A formação do professor para as novas tecnologias na educação. 2004. 52 f. Trabalho de Conclusão de Curso (Pós-Graduação) - Universidade do Extremo Sul Catarinense, Criciúma, 2004. https://doi.org/10.17143/ciaed/xxiilciaed.2017.00304

MAIA, R. C. M. Redes cívicas e internet: efeitos democráticos do associativismo. Logos, v. 14, n. 2, p. $43-62,2007$.

MARIN, D. Vantagens e desvantagens apontadas por professores de matemática no uso de tecnologia de informação e comunicação no ensino superior. DiversaPrática, v. 1, n. 1, 2012.

MARTINI, C. M.; BUENO, J. L. P. O desafio das tecnologias de informação e comunicação na formação inicial dos professores de matemática. Educação Matemática Pesquisa, v. 16, n. 2, 2014. https://doi.org/10.29327/1.3056.3-1

MELARA, A.; RAMPELOTTO, M.; LINASSI, P. S. da. A Formação de Surdos e as Tecnologias de Informação e Comunicação: Discutindo Potencialidades. In: SEMINÁRIO POLÍTICAS PÚBLICAS E AÇÕES AFIRMATIVAS, 1., 2015, Santa Catarina, Anais [...], 2015. p. 1-15. 
MOURA, E.; BRANDÃO, E. O uso das tecnologias digitais na modificação da prática educativa escolar. Revista Científica Fazer, 2013.

NUNES, J. B. C. et al. Cultura digital: retrato do uso das tecnologias no Estado do Ceará. Fortaleza. EdUECE, 2014.

PONTES, J. P. Tecnologias de informação e comunicação na formação de professores: Que desafios? Revista Ibero-Americana de Educación, n. 24, p. 63-90. 2000.

PRATA-LINHARES, M. M.; ARRUDA, R. D. Inovação e integração das tecnologias digitais na docência universitária: conceitos e relações. Reflexão e Ação, v. 25, n. 2, p. 250-268. https://doi.org/10.17058/rea.v25i2.8843

RODRIGUES, M. A. As tecnologias digitais na formação de professores: construção de conhecimentos e cultura digital como elementos de qualificação pedagógica. 2012. 46 f. Trabalho de Conclusão de Curso (Especialização) - Centro

Interdisciplinar de novas tecnologias na educação da Universidade Federal do Rio Grande do Sul, Porto Alegre, 2012. https://doi. org/10.29289/259453942018v28s1059

ROLANDO, L. G. R.; VASCONCELLOS, R.F.R.R; MORENO, E.L.; SALVADOR, D.R.; SALVADOR D. F.; LUZ, M.R.M.P. Integração entre Internet e Prática Docente de Química. Revista virtual de Química, v. 7, n. 3, 2015.

ROSA, A. B Aula diferenciada e seus efeitos na aprendizagem dos alunos: o que os professores de Biologia têm a dizer sobre isso? 2012. 43 f. Trabalho de Conclusão de Curso (Graduação) - Universidade Federal do Rio Grande do Sul, Porto Alegre, 2012. https://doi.org/10.29289/259453942018v28s 1059

SÁ, C. S. S.; SANTOS, W. L. P. dos. Constituição de identidades em um curso de licenciatura em química. Revista Brasileira de Educação, v. 22, n. 69, 2017. https://doi.org/10.1590/s1413-24782017226917

SANTOS, A. P. A.; CARLI, B.; CANO, P. F. A Acessibilidade da Informação para Deficientes Visuais e Auditivos. Anagrama: Revista Científica Interdisciplinar da Graduação, v. 4, n. 4, 2011.

SEEGGER, V.; CANES, S. E.; GARCIA, C. A. Estratégias Tecnológicas na Prática Pedagógica. Monografias Ambientais, v. 8, n. 8, p. 1887-1899, 2012. https://doi.org/10.5902/223613086196

SILVA, C. T. A.; GARÍGLIO, J. Â. A formação continuada de professores para o uso das Tecnologias da Informação e Comunicação (TIC): o caso do projeto Escolas em Rede, da Rede Estadual de Educação de Minas Gerais. Revista Diálogo Educacional, v. 10, n. 31, 2010. https://doi.org/10.7213/rde.v10i31.2380

SILVA, J. R. R. da. As tecnologias da informação e comunicação no ensino de Geografia: formação e prática docente. 2015. 176 f. Dissertação (Mestrado em Ciências Humanas) - Universidade Federal de Uberlândia, Uberlândia, 2015. https://doi. org/10.14393/19834071.v26.n2.2017.38402 
SILVERMAN, D. Interpretação de dados qualitativos: métodos para análise de entrevistas, textos e interações. Porto Alegre: Bookman, 2009. 376p.

Recebido em: 21/12/2017.

Aprovado em: 12/12/2018.

Publicado em: 31/12/2019.

\section{Endereço para correspondência:}

Universidade Estadual do Ceará (UECE)

Av. Dr. Silas Munguba, 1700 - Itaperi

60714-903, Fortaleza, CE, Brasil

\section{Autores:}

Francisco Nunes Sousa Moura

Universidade Estadual do Ceará (UECE).

Orcid: http://orcid.org/0000-0002-8745-5010

E-mail: nunes.moura@aluno.uece.br

Shirliane de AraúJo Sousa

Universidade Estadual do Ceará (UECE).

Orcid: http://orcid.org/0000-0001-7230-6859

E-mail: shirliane.araujo@uece.br

Jones Baroni Ferreira Menezes

Universidade Estadual do Ceará (UECE).

Orcid: http://orcid.org/0000-0002-9193-3994

E-mail: jones.baroni@uece.br 